\title{
Whole-brain Radiation Therapy for Breast Cancer Patients with Dural Metastasis Without Concomitant Brain Metastasis and Leptomeningeal Metastasis
}

MASAKUNI SAKAGUCHI, TOSHIYA MAEBAYASHI, TAKUYA AIZAWA and NAOYA ISHIBASHI

Department of Radiology, Nihon University School of Medicine, Tokyo, Japan

\begin{abstract}
Aim: To evaluate outcomes of breast cancer patients with confirmed dural metastasis (DM) alone who received whole-brain radiation therapy (WBRT). Patients and Methods: The medical records of thirty-three breast cancer patients who received WBRT to treat intracranial metastasis were retrospectively reviewed. The clinical presentation of DM-only was compared with that of brain metastasis (BM)/leptomeningeal metastasis (LM). Results: Eight patients had DM and 25 patients had BM/LM. Median survival was 12 months in patients with DM and 7 months in those with BM/LM. Multivariate analysis found that only a Karnofsky performance status of $\geq 70$ was significantly associated with improved OS. DM did not cause the death of any patient. Symptoms did not worsen in any DM patient. Conclusion: WBRT can be considered for patients with DM alone for symptom improvement and preventing DM-related death.
\end{abstract}

Intracranial metastases are the most common neurological complications of cancer and mostly involve the parenchyma, but metastases to the leptomeninges and dura also occur. All affect survival and prognosis (1-3). Dural metastases (DM) are usually direct extensions of skull bone metastases or of hematogenous origin, are relatively rare $(4,5)$, and are usually concomitant with brain metastasis (BM) or leptomeningeal metastasis (LM). DM rarely occur alone without extension from a skull bone metastasis. The treatment of DM differs from that of BM and LM because of the presence of the blood-brain barrier (BBB) and bloodcerebrospinal fluid barrier (BCSFB) $(6,7)$. Intracranial metastases must be evaluated to determine whether they are

Correspondence to: Masakuni Sakaguchi, Department of Radiology, Nihon University School of Medicine, 30-1, Oyaguchi Kami-cho, Itabashi-ku, Tokyo, 173-8610, Japan. Tel: +81 339728111 ext.2552, Fax: +81 339582454, e-mail: sakaguchi.masakuni@nihon-u.ac.jp

Key Words: Dural metastasis, brain metastasis, leptomeningeal metastasis, whole brain radiation therapy. inside the $\mathrm{BBB}$ and $\mathrm{BCSFB}$, which suppresses transfer of chemotherapy agents into the brain parenchyma. DM exists outside of these barriers and is more easily exposed to chemotherapy than other intracranial metastases $(6,7)$. Whole-brain radiation therapy (WBRT) is useful for treating $\mathrm{BM} / \mathrm{LM}$ and DM with concomitant BM/LM because of the limited access to chemotherapy, but the effectiveness of WBRT for DM alone without concomitant BM/DM is not known. The clinical benefit of WBRT in the absence of parenchymal metastasis is unclear. Previous reports of WBRT for DM are biased by small patient samples, the inclusion of patients with concomitant BM/LM, DM after resection of $\mathrm{BM}$, direct dural involvement from skull bone metastasis, and different treatment regimens (8-10). Previous reports did not distinguish treatment effectiveness and overall survival (OS) of patients with DM and BM/LM from those of patients with DM alone. DM from skull bone metastasis can be treated by surgery and/or partial radiotherapy, but that solves only part of the problem and may interfere with subsequent WBRT. This study retrospectively evaluated breast cancer patients with confirmed DM who only received WBRT and compared the clinical characteristics and outcomes of those with DM alone or BM/LM.

\section{Patients and Methods}

Patients. The medical records of breast cancer patients who received WBRT between January 2007 and April 2018 to treat intracranial metastasis were retrospectively reviewed. The clinical presentation of DM-only was compared with that of BM/LM. Data retrieval began in 2007 because inclusion of detailed imaging results in the electronic medical records started then, allowing a more complete evaluation of the clinical course of patients. DM only patients were all have metastases originating from the breast cancer by chance. Eligibility was limited to breast cancer patients.

Diagnosis. Patients were evaluated by enhanced head magnetic resonance imaging (MRI) to distinguish those with DM alone from those with BM/LM. T1- and T2-weighted, fluid attenuated inversion recovery (FLAIR), and diffusion-weighted images were obtained in 
the transverse plane. Enhanced T1-weighted images with fat suppression were obtained in the transverse, sagittal, and coronal planes after intravenous administration of gadolinium. On MRI, DM typically appear as a thickening of the dura mater. A nodular pattern is possible. Absence of the BBB accounts for the intense, homogeneous contrast enhancement. Unlike LM, dural enhancement and thickening do not continue along the gyri and sulci. In LM, MRI findings include diffuse linear leptomeningeal enhancement along the gyri and sulci or multiple enhancing extra-axial nodules on the surfaces of the brain and ventricles. Computed tomography (CT) was used to detect bone metastases and rule-out direct extension from bone metastases. Patients with concomitant BM/LM confirmed radiographically or by positive cerebrospinal fluid cytology were excluded. The presence of other distant metastases and the status of the primary lesion were evaluated by whole body CT. Primary tumor status was favorable if no enlargement was found of CT and/or MRI for at least 3 months compared with its original size. Even with extracranial metastases, the primary tumor status was judged to be favorable if it was not viable or had not enlarged for at least 3 months. Evaluation of symptoms included the presence of headache, nausea, vomiting, cranial nerve dysfunction (e.g., visual change, diplopia, trigeminal nerve dysfunction, and facial weakness), mental status, seizures, and difficulty walking.

Radiation therapy. Patients with DM alone without evidence of $\mathrm{BM} / \mathrm{LM}$ were started on anticancer drugs. WBRT was indicated by patient symptoms or worsening of MRI findings despite administration of anticancer drugs and a DM that is surgically inaccessible or widespread. DM patients with extensive dura matter thickening, multiple nodular lesions, or concomitant multiple skull bone metastases, not indicated for partial radiotherapy, received WBRT. Initial WBRT was considered in patients with LM or BM or both plus symptoms. WBRT was delivered by a CT simulator, four opposing lateral fields, and the in-field technique. WBRT with 10 MV photon beams was delivered once daily 5 days per week. Doses were given in fractions of $2.5,3$, or $4 \mathrm{~Gy}$, with a total dose of 20-40 Gy. The basic radiation schedule was $3 \mathrm{~Gy} /$ fraction, with a total of $30 \mathrm{~Gy}$. Patients with a condition indicative of a poor prognosis and a short course received $4 \mathrm{~Gy} /$ fraction, with a total of 20 Gy. Those with a good prognosis and expected long course received an increased dose. No patients received whole spine irradiation and intrathecal chemotherapy.

Treatment response of image findings. Treatment response was monitored by enhanced head MRI performed every 3-6 months and scored by the time of peak response. Complete response (CR) was defined as the disappearance of DM on enhanced MRI. Partial response (PR) was a reduction in dura mater thickening and nodules. Progressive disease (PD) was an increase in dura mater thickening and nodules. Stable disease (SD) was a change in DM insufficient to qualify as PD. Local recurrence after WBRT included the appearance of regrowth of thickening or nodular enhancement of the dura matter on enhanced MRI.

Treatment response of symptom. CR was defined as the disappearance of clinical symptoms. PR was an improvement of symptoms. PD was a worsening of symptoms. SD was a no change in symptoms. Symptomatic patients were given steroids, glycerol, and antiepileptic drugs as palliative care and for the prevention of WBRT toxicity. Consequently, treatment response could not be assessed in patients who were simultaneously treated with these
Table I. Baseline clinical characteristics of patients.

\begin{tabular}{|c|c|}
\hline Characteristic & Value $(\%)$ \\
\hline Patients & 33 \\
\hline \multicolumn{2}{|l|}{ Age, years } \\
\hline Median (range) & $35-78$ \\
\hline Median & 55 \\
\hline$\leq 65$ & $25(76)$ \\
\hline$>65$ & $8(24)$ \\
\hline \multicolumn{2}{|l|}{$\mathrm{KPS}^{\mathrm{a}}, \mathrm{n}$} \\
\hline$\geq 70$ & $21(66)$ \\
\hline$<70$ & $12(34)$ \\
\hline \multicolumn{2}{|l|}{ Symptom, $\mathrm{n}$} \\
\hline Yes & $21(64)$ \\
\hline No & $12(36)$ \\
\hline \multicolumn{2}{|l|}{ Total dose (Gy), n } \\
\hline 20 & $2(6)$ \\
\hline 30 & $20(61)$ \\
\hline 37.5 & $10(30)$ \\
\hline 40 & $1(3)$ \\
\hline \multicolumn{2}{|c|}{ Extracranial metastases, $\mathrm{n}$} \\
\hline 0 & $4(12)$ \\
\hline 1 & $10(30)$ \\
\hline 2 & $10(30)$ \\
\hline 3 & $9(28)$ \\
\hline \multicolumn{2}{|c|}{ Type of the metastasis, $n$} \\
\hline $\mathrm{BM}^{\mathrm{b}} / \mathrm{LM}^{\mathrm{c}}$ & $25(76)$ \\
\hline $\mathrm{DM}^{\mathrm{d}}$ & $8(24)$ \\
\hline \multicolumn{2}{|l|}{ 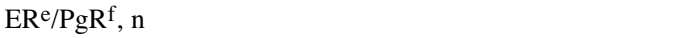 } \\
\hline positive & $18(55)$ \\
\hline negative & $13(39)$ \\
\hline unknown & $2(6)$ \\
\hline \multicolumn{2}{|l|}{ HER2 $2, n$} \\
\hline positive & $7(21)$ \\
\hline negative & $24(73)$ \\
\hline unknown & $2(6)$ \\
\hline \multicolumn{2}{|l|}{$\mathrm{Ki67}, \mathrm{n}$} \\
\hline$\geq 15$ & $18(55)$ \\
\hline$<15$ & $6(18)$ \\
\hline unknown & $9(27)$ \\
\hline \multicolumn{2}{|c|}{ Surgery plus WBRTh, $\mathrm{n}$} \\
\hline Yes & $1(3)$ \\
\hline No & $32(97)$ \\
\hline
\end{tabular}

aKarnofsky performance status, bbrain metastasis, cleptomeningeal metastasis, ${ }^{d}$ dural metastasis, ${ }^{e}$ estrogen receptor, ${ }^{f}$ progesterone receptor, ghuman epidermal growth factor receptor-2, $\mathrm{h}_{\text {whole-brain radiation }}$ therapy.

drugs and WBRT. If steroids and glycerol were used to reduce WBRT toxicity and then discontinued after WBRT, then treatment response was assessed by subsequent changes in symptoms. If symptoms such as headache and nausea remained unchanged or worsened, then the treatment response was assessed during the subsequent follow-up evaluation to distinguish it from the side effects of WBRT.

WBRT toxicity. Adverse events associated with WBRT were monitored and defined following Common Terminology Criteria for Adverse Events version 4.0, with toxicity graded as mild (CTC 
Table II. Patient characteristics of dural metastasis.

\begin{tabular}{|c|c|c|c|c|c|c|c|c|c|c|c|c|c|c|}
\hline Number & Age & $\begin{array}{l}\text { Time to } \\
\text { dural } \\
\text { metastasis }\end{array}$ & $\mathrm{KPS}^{\mathrm{a}}$ & Symptom & $\begin{array}{l}\text { Lesion } \\
\text { site }\end{array}$ & Form & $\begin{array}{c}\text { Primary } \\
\text { status }\end{array}$ & $\begin{array}{c}\text { Other } \\
\text { metastasis }\end{array}$ & $\mathrm{ER} / \mathrm{PgR}^{\mathrm{c}}$ & HER $2^{d}$ & $\begin{array}{l}\text { Ki67 } \\
\geq 15 \%\end{array}$ & $\begin{array}{l}\text { Previous } \\
\text { treatment }\end{array}$ & $\begin{array}{c}\text { After } \\
\text { WBRT }^{\mathrm{i}}\end{array}$ & $\begin{array}{c}\text { Symptom } \\
\text { response }\end{array}$ \\
\hline 1 & 61 & 32 & 80 & Diplopia & Skull base & $\begin{array}{c}\text { Dural } \\
\text { thickening }\end{array}$ & Stable & Bone & + & - & + & HTxe & $\begin{array}{l}\text { CTx+ } \\
\text { HTx }\end{array}$ & $\mathrm{CR}^{\mathrm{j}}$ \\
\hline 2 & 77 & 174 & 60 & $\begin{array}{l}\text { Head ache, } \\
\text { memory } \\
\text { disturbance }\end{array}$ & $\begin{array}{c}\text { Left } \\
\text { hemisphere }\end{array}$ & $\begin{array}{c}\text { Dural } \\
\text { thickening }\end{array}$ & Stable & $\begin{array}{l}\text { Bone, } \\
\text { LN }^{\mathrm{b}}\end{array}$ & + & - & + & $\begin{array}{l}\text { CTx+ } \\
\text { HTx }\end{array}$ & - & $\mathrm{CR}$ \\
\hline 3 & 53 & 0 & 80 & $\begin{array}{l}\text { Head ache, } \\
\text { facial } \\
\text { sensory } \\
\text { disorder }\end{array}$ & $\begin{array}{c}\text { Left } \\
\text { hemisphere }\end{array}$ & Nudular & Unstable & $\begin{array}{c}\text { Bone, } \\
\text { LN, } \\
\text { liver }\end{array}$ & + & - & + & CTx & $\begin{array}{l}\text { CTx+ } \\
\text { HTx }\end{array}$ & $\mathrm{SD}^{\mathrm{k}}$ \\
\hline 4 & 58 & 53 & 80 & $\begin{array}{l}\text { Right arm } \\
\text { numbness }\end{array}$ & $\begin{array}{c}\text { Left } \\
\text { hemisphere }\end{array}$ & $\begin{array}{c}\text { Dural } \\
\text { thickening }\end{array}$ & Stable & Bone & + & - & - & $\begin{array}{l}\text { CTx+ } \\
\text { HTx }\end{array}$ & - & $\mathrm{CR}$ \\
\hline 5 & 64 & 20 & 80 & $\begin{array}{l}\text { Head ache, } \\
\text { nausea }\end{array}$ & Parietal & Nodular & Unstable & $\begin{array}{c}\text { Bone, } \\
\text { LN, } \\
\text { liver }\end{array}$ & + & - & Unknown & $\begin{array}{l}\text { Opeg for } \\
\mathrm{DM}^{\mathrm{h}_{+}} \\
\text {HTx }\end{array}$ & Unknown & $\mathrm{PR}^{1}$ \\
\hline 6 & 55 & 120 & 80 & $\begin{array}{c}\text { Cranial } \\
\text { nerve palsy }\end{array}$ & Skull base & $\begin{array}{c}\text { Dural } \\
\text { thickening }\end{array}$ & Unstable & Lung & + & - & Unknown & $\begin{array}{l}\text { CTx+ } \\
\text { HTx }\end{array}$ & HTx & PR \\
\hline 7 & 49 & 192 & 90 & Head ache & $\begin{array}{c}\text { Left } \\
\text { hemisphere }\end{array}$ & $\begin{array}{c}\text { Dural } \\
\text { thickening }\end{array}$ & Stable & - & - & + & Unknown & $\begin{array}{l}\text { CTx+ } \\
\text { HTx }\end{array}$ & CTx & $\mathrm{CR}$ \\
\hline 8 & 61 & 39 & 70 & $\begin{array}{c}\text { Nausea, } \\
\text { diplopia, } \\
\text { facial } \\
\text { sensory } \\
\text { disorder }\end{array}$ & $\begin{array}{c}\text { Bilateral } \\
\text { hemisphere, } \\
\text { skull base }\end{array}$ & $\begin{array}{c}\text { Dural } \\
\text { thickening } \\
\text { and } \\
\text { nodular }\end{array}$ & Stable & $\begin{array}{c}\text { Bone, } \\
\text { liver, } \\
\text { LN }\end{array}$ & + & - & + & HTx & HTx & PR \\
\hline
\end{tabular}

aKarnofsky performance status, blymph node, cestrogen receptor/progesteron receptor, dhuman epidermal growth factor receptor-2, ehormontherapy, $\mathrm{f}_{\text {chemotherapy, }} \mathrm{g}_{\text {operation, }} \mathrm{h}_{\text {dural metastasis, }}{ }^{\mathrm{i}}$ whole brain radiation therapy, $\mathrm{j}_{\text {complete response, }} \mathrm{k}_{\text {stable disease, }}{ }^{1}$ partial response.

grade 1), moderate (CTC grade 2), severe (CTC grade 3), or lifethreatening (CTC grade 4) (11).

Statistical analysis. The OS of WBRT patients was estimated by the Kaplan-Meier method and was defined as the interval from the last day of treatment to the date of death or the most recent follow-up as of December 2017. Patients who survived until the end of the follow-up period without an event were censored. Age, Karnofsky performance status (KPS), symptoms, radiation dose, extracranial metastasis, and type of metastasis were evaluated as prognostic factors. Local control was calculated as the interval from the last day of the treatment until the recurrence of symptoms. Data from patients who died with no evidence of recurrence were censored. Patient variables that were associated with survival were identified by univariate analysis and the log-rank test, and those with a statistically significant association were included in a subsequent multivariate analysis. $p$-Values $<0.05$ were considered statistically significant. Statistical analysis was performed using the SPSS 15.0 J statistical software (SSPS Inc., Chicago, IL, USA).

Patient consent. This retrospective study evaluated patient characteristics, diagnosis, and treatment retrieved from electronic medical records. All procedures followed the ethical guidelines of the 1964 Helsinki declaration and its later amendments or comparable ethical standards. Patient records and information were anonymized and de-identified prior to evaluation in this study. Written patient's consent to participate was waived for the retrospective study. Patients were informed before the start of treatment that their data might be used in future investigations even if the outcome was death, and all consented to the use of their data. Patients were informed of the benefits and risks of the chemotherapy or WBRT that would be administered and provided written informed consent before inclusion.

\section{Results}

Patient characteristics and treatment. Thirty-three women (median age, 55 years; range, 35-78 years) with intracranial metastasis of breast cancer and treated by WBRT at Nihon University Itabashi Hospital between January 2007 and April 2018 as described above were enrolled. Eight patients had DM and 25 patients had BM/LM. The baseline patient characteristics are summarized in Table I. Twelve of the 33 patients $(34 \%)$ had a KPS of $<70$, and $21(64 \%)$ reported symptoms. Ten patients $(30 \%)$ had extracranial metastases at one or two sites. Many patients with advanced primary tumors had metastasis to other organs. Twelve patients who received WBRT started with $3 \mathrm{~Gy} /$ fraction and received a 


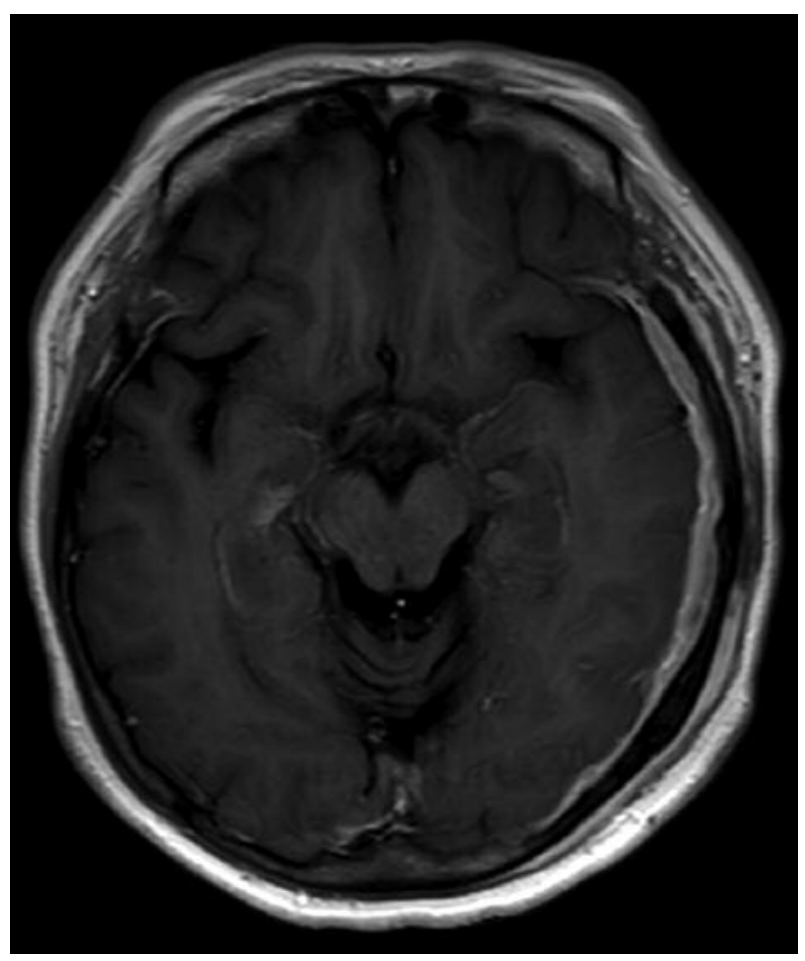

Figure 1. Enhanced MRI showing dural metastasis with wide dural thickening and enhancement of the left hemisphere.

total of $30 \mathrm{~Gy}$. All DM patients experienced symptoms, and many with advanced disease had metastases and had already received chemotherapy chemotherapy or/and hormone therapy (Table II). No DM patients were indicated for partial radiotherapy. The lesions were all extensive, and all DM patients were given WBRT. One patient with a large nodular DM underwent surgery prior to WBRT.

DM imaging. All patients had gadolinium-enhanced brain MRI scans available for review. Six DM patients had a single, wide thickening of the dura matter; two had nodular thickening (Figures 1,2 and 3). Five DM patients were in the temporal hemisphere $(62.5 \%)$, and three were at the base of the skull $(37.5 \%)$. One DM patient had a subdural hematoma. The venous sinuses and brain parenchyma were not involved in any patients.

Symptoms. At the start of WBRT, 13 patients with BM/LM (50\%) and eight patients with DM (100\%) reported some symptoms. The most common symptoms in DM patients were headache and nausea in five, followed by cranial nerve dysfunction (diplopia and facial sensory weakness) in three. The DM of the skull base was associated with symptoms of cranial nerve compression.

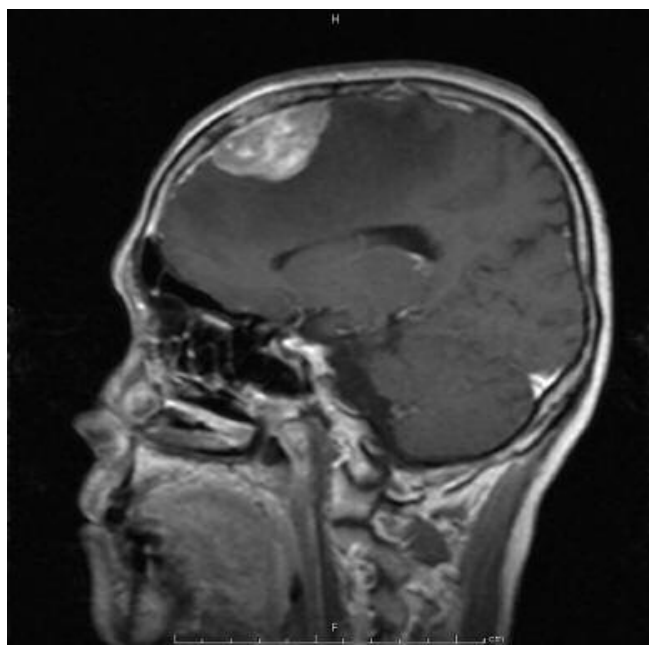

Figure 2. Enhanced MRI showing dural partial thickening and nodular change in the temporal region.

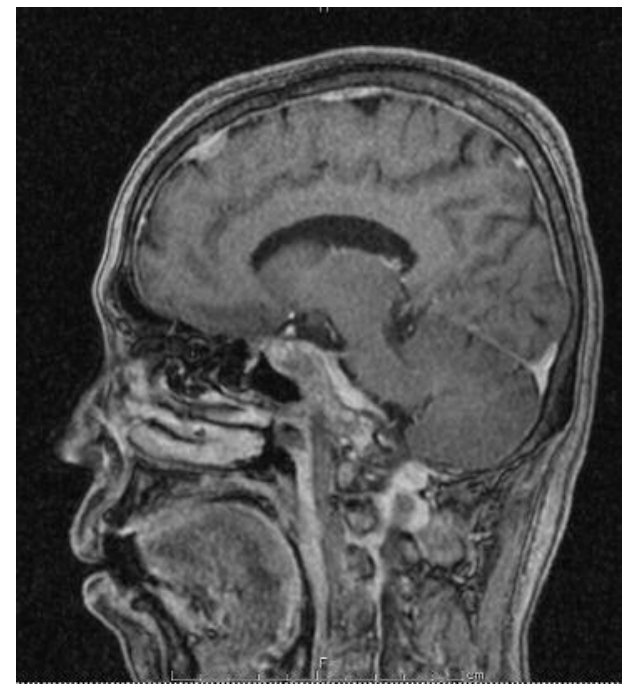

Figure 3. Enhanced MRI showing dural thickening of the skull base.

Outcomes. The median duration of follow-up was 6 (range $=1$ 31) months. Twenty patients, including four DM patients, died during follow-up. The cause of death in all 20 was the primary disease or a condition related to the primary disease. DM did not cause the death of any patient. The median survival was 7 (range=1-31) months; 1-year survival was 35.3\% (Figure 4). Median survival was 12 months in patients with DM and 7 months in those with BM/LM (Figure 5). Univariate analysis found that only a Karnofsky performance status (KPS) of $\geq 70$ was significantly associated with improved OS. In multivariate analysis, KPS $(\mathrm{HR}=0.221,95 \% \mathrm{CI}=0.071-0.689 ; p<0.009)$ 


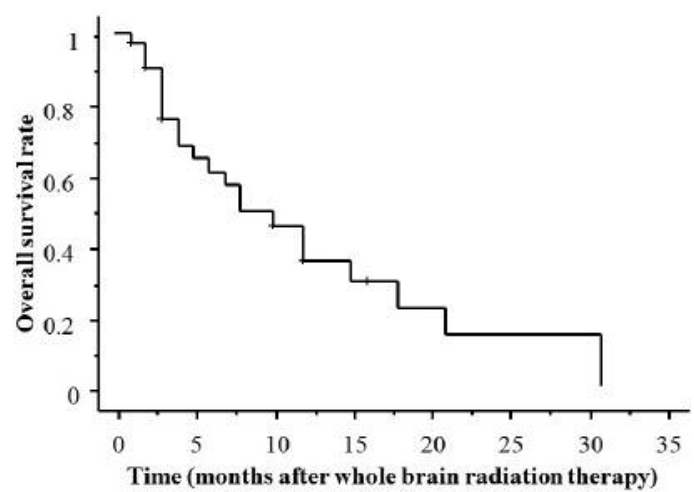

Figure 4. One-year survival rate was $35.3 \%$ in patients with intracranial metastasis from breast cancer.

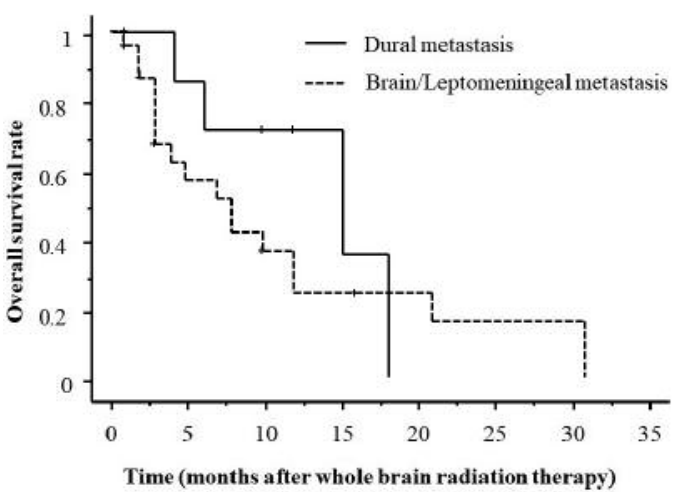

Figure 5. Median survival was 12 months with DM and 7 months with $B M / L M$.

Table III. Univariate and multivariate analysis of factors that affect overall survival.

\begin{tabular}{|c|c|c|c|c|}
\hline \multirow[b]{2}{*}{ Variable } & \multirow{2}{*}{$\begin{array}{c}\text { Univariate } \\
p \text {-Value }\end{array}$} & \multicolumn{3}{|c|}{ Multivariate } \\
\hline & & $\mathrm{HR}^{\mathrm{e}}$ & $95 \% \mathrm{CI}^{\mathrm{f}}$ & $p$-Value \\
\hline Age, $>60 v s . \leq 60$ years & 0.587 & 0.812 & $0.317-2.079$ & 0.664 \\
\hline $\mathrm{KPS}^{\mathrm{a}},<70$ vs. $\geq 70$ & 0.009 & 0.221 & $0.071-0.689$ & 0.009 \\
\hline Symptom, Yes vs. No & 0.560 & 0.617 & $0.188-2.028$ & 0.426 \\
\hline Radiation dose, $<37.5$ Gy $v s . \geq 37.5$ Gy & 0.996 & 0.887 & $0.290-2.713$ & 0.834 \\
\hline Extracranial metastases, $\leq 1 v s . \geq 2$ & 0.300 & 0.284 & $0.064-1.253$ & 0.096 \\
\hline Type of metastasis, $\mathrm{BM}^{\mathrm{b}} / \mathrm{LM}^{\mathrm{c}} v s . \mathrm{DM}^{\mathrm{d}}$ & 0.340 & 1.698 & $0.389-7.406$ & 0.481 \\
\hline
\end{tabular}

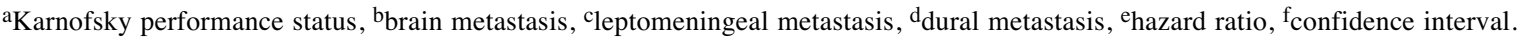

was independently associated with prognosis (Table III). There was no significant difference of survival in patients with $\mathrm{BM} / \mathrm{LM}$ and in those with DM only.

Follow-up MRI was not performed after WBRT when it was administered as palliative radiotherapy. Especially a more complete evaluation for BM/LM was impossible because of lack of follow-up MRI. Five of the eight DM patients were evaluated by enhanced brain MRI after treatment. CR was achieved in two of the patients. In one, much of the lesion had been removed by the preceding surgery. PR was seen in two patients and SD in one. No DM patient experienced PD. No DM patient developed an intracranial lesion after WBRT. In the eight DM patients, WBRT was effective against symptoms, CR was achieved in four, PR in three, and SD in one. Symptoms did not worsen in any DM patient after WBRT. A more complete evaluation for BM/LM was impossible because of lack of complete data in the medical records or short follow-up. Documentation of response to treatment for BM/LM was often not reported according to current oncology standards. Several medical records of $\mathrm{BM} / \mathrm{LM}$ described the responses in general terms, such as "good clinical effect," "improvement of symptom,", instead of defined endpoints.

WBRT toxicity. The most frequent acute toxicities associated with WBRT included grade 1 headache, nausea, dermatitis and hair loss. No severe adverse events were noted.

\section{Discussion}

The occurrence of BM has been shown to vary with tumor stage at initial diagnosis, with central nervous system invasion estimated to occur in $13.4 \%$ of patients presenting with stage IV breast cancer tumors (12). DM is found in $9 \%$ of patients with systemic cancer at autopsy. In $4 \%$ of these patients, it represents the only site of intracranial involvement (13). Breast cancer was the most common primary tumor associated with DM, followed by prostate cancer (10). In this study, the presence of DM was required for inclusion, and only eight of 33 patients found to have DM only. Although there were 
several prostate cancer patients with DM in contact with and direct extensions of concomitant skull bone metastases, only breast cancer patients were included in the criteria. In this study, all patients with DM only had breast cancer, and it is expected that additional cases like these will be encountered in the future.

The OS of breast cancer patients with BM is poor, ranging from 3 to 6 months (14), but may be increased depending on estrogen, progesterone, and human epidermal growth factor receptor status, as well as the use of molecular targeted therapy (15). The median survival of patients with BM/LM was 7 months, and that of patients with DM only was 12 months, both of which compare favorably with previous reports in breast cancer patients with BM/LM. This might be attributable to the number of patients with DM in this study, the use of molecular targeted drugs, differences in anticancer drug regimens, or the inclusion of patients who continued anticancer drugs after WBRT. The absence of a significant difference in the median survival of the DM only and $\mathrm{BM} / \mathrm{LM}$ patients in this study might also have resulted from small number of patients. Seven (87.5\%) DM only patients had active bone, lung, liver, or lymph node lesions. Patients with DM had more progression of systemic disease and receiving aggressive systemic chemotherapy. Although multivariate analysis found that additional metastases and form of metastasis also did not significantly influence OS, DM tends to be have good prognosis. Multivariate analysis did find that KPS significantly influenced prognosis of patients with DM and BM/LM. The study results are consistent with previous reports of the prognostic value of KPS, absence of extracranial, cerebellar metastases, and combination chemotherapy in patients with BM after WBRT (16). It is expected that the presence of a good general condition improves prognosis.

Systemic chemotherapy after local treatment of BM can prolong the survival of breast cancer patients (17) because of its effects on other metastases $(6,18)$. In patients with $\mathrm{BM} / \mathrm{LM}, \mathrm{WBRT}$ is an important treatment because the BBB reduces the efficacy of systemic chemotherapy by reducing exposure to cytotoxic drugs. Systemic chemotherapy is indicated for DM patients because the metastatic cells are located outside of the BBB and BCSFB. Choosing whether to give WBRT to patients with DM only is complicated by the absence of metastasis to the brain parenchyma and consideration of side effects associated with WBRT. There is clinical dilemma that WBRT was performed regardless of no parenchymal metastasis. Focal radiotherapy plus surgery can be considered for DM that occur in a limited area, but focal radiation therapy will interfere with WBRT if it is needed for intracranial metastasis that occurs later. Although the contribution of WBRT to the survival of patients with DM only is unknown, it offers symptomatic relief and intracranial control.
The most common symptoms in patients with DM-only were headache followed by cranial neuropathy and were similar to those reported in another study (10). Headache may be indicative of traction on the dura, invasion of venous sinuses, or increased intracranial pressure alone or combined with subdural hemorrhage $(5,19)$. Subdural hematoma should be considered when evaluating headache symptoms. Cranial nerve palsies can occur when the DM is located at the base of the skull $(10,20)$. Compression of the cavernous sinus is associated with multiple cranial neuropathies, and focal weakness can result from compression or invasion of the underlying brain parenchyma by the DM (20). In this study, most symptoms disappeared after WBRT and did not worsen or reappear until death or the end of the study. WBRT was effective in treating symptoms, especially those associated with DM derived from extension of cranial bone metastasis, which were the most common type $(57 \%)$ to cause symptom $(5,21)$.

Only five DM-only patients were evaluated by enhanced MRI after WBRT, but none of the findings indicated PD, and no new intracranial lesions appeared. The causes of death were related to progression of the primary lesion or deterioration of their general condition because of cancer. No patient deaths were related to the DM. The results indicated that even if WBRT did not contribute to survival, it was very effective for controlling DM symptoms and preventing additional intracranial metastases.

The most frequent WBRT acute toxicity symptoms were headache, fatigue, nausea, vomiting and hair loss, most of which were grade 1 and manageable with steroids. WBRT can be recommended to DM alone for symptom improvement and prevention of death caused by DM. As the survival prognosis of DM is 12 months, late side effects are not a consideration. In patients with few additional metastases or with the possibility of treatment with additional anticancer or molecular-targeted drugs, long-term toxicity, with symptoms such as memory loss, intellectual impairment, or ataxia, is of concern. Memory disorders after WBRT have prompted investigations of the effectiveness of hippocampal-sparing WBRT in patients who can expect long-term survival $(22,23)$. Memantine may be effective for preventing memory decline after WBRT (24).

We clarified the outcome of DM-only patients who received WBRT however, the study limitations include its retrospective design and the small number of DM only patients, which made it impossible to compare changes in symptoms and imaging findings in patients with BM/LM and those with DM only. This limitation may be addressed in future multicenter international.

\section{Conclusion}

WBRT can be considered for patients with DM alone for symptom improvement and preventing DM related death. 


\section{Competing Interests}

The Authors have no financial disclosures.

\section{Conflicts of Interest}

The Authors declare no conflicts of interest in regard to this study.

\section{References}

1 Taillibert $\mathrm{S}$ and Hildebrand J: Treatment of central nervous system metastases: parenchymal, epidural, and leptomeningeal. Curr Opin Oncol 18: 637-643, 2006.

2 Waki F, Ando M, Takashima A, Yonemori K, Nokihara H, Miyake M, Tateishi U, Tsuta K, Shimada Y, Fujiwara Y and Tamura T: Prognostic factors and clinical outcomes in patients with leptomeningeal metastasis from solid tumors. J Neurooncol 93: 205-212, 2009.

3 Luo J, Zhu H, Tang Y, Wang H, Zhou X, Lu X, Zhang S and Li $\mathrm{Y}$ : Analysis of prognostic factors and comparison of prognostic index scores in patients with brain metastases after whole-brain radiotherapy. Int J Clin Exp Med 7: 5217-5225, 2014.

4 Coleman RE: Metastatic bone disease: clinical features, pathophysiology and treatment strategies. Cancer Treat Rev 27: 165-176, 2001.

5 Laigle-Donadey F1, Taillibert S, Mokhtari K, Hildebrand J and Delattre JY: J Neurooncol 75: 57-61, 2005.

6 Oechsle K, Lange-Brock V, Kruell A, Bokemeyer C and de Wit M: Prognostic factors and treatment options in patients with leptomeningeal metastases of different primary tumors: a retrospective analysis. J Cancer Res Clin Oncol 136: 1729-1735, 2010.

7 Boogerd W, van den Bent MJ, Koehler PJ, Heimans JJ, van der Sande JJ, Aaronson NK, Hart AA, Benraadt J and Vecht ChJ: The relevance of intraventricular chemotherapy for leptomeningeal metastasis in breast cancer: a randomised study. Eur J Cancer 40: 2726-2733, 2004.

8 Kleinschmidt-DeMasters BK: Dural metastases. A retrospective surgical and autopsy series. Arch Pathol Lab Med 125: 880-887, 2001 .

9 Laigle-Donadey F, Taillibert S, Mokhtari K, Hildebrand J and Delattre JY: Dural metastases. J Neurooncol 75: 57-61, 2005.

10 Nayak L, Abrey LE and Iwamoto FM: Intracranial dural metastases. Cancer 115: 1947-1953, 2009.

11 U.S. Department of Health and Human Services, National Institutes of Health, National Cancer Institute: Common Terminology Criteria for Adverse Events (CTCAE). Version 4.0. May 29th, 2009. http://evs.nci.nih.gov/ftp1/CTCAE/CTCAE_ 4.03_2010-06-14_QuickReference_8.5x11.pdf. Accessed 18th May 2015.

12 Crivellari D, Pagani O, Veronesi A, Lombardi D, Nolè F, Thürlimann B, Hess D, Borner M, Bauer J, Martinelli G, Graffeo R, Sessa C and Goldhirsch A; International Breast Cancer Study Group: High incidence of central nervous system involvement in patients with metastatic or locally advanced breast cancer treated with epirubicin and docetaxel. Ann Oncol 12: 353-356, 2001 .
13 Posner JB: Intracranial metastases. In: Neurologic Complications of Cancer. FA Davis, Philadelphia 109: 77-82, 1995.

14 Mahmoud-Ahmed AS, Suh JH, Lee SY, Crownover RL and Barnett GH: Results of whole brain radiotherapy in patients with brain metastases from breast cancer: a retrospective study. Int J Radiat Oncol Biol Phys 54: 810-817, 2002.

15 Miller JA, Kotecha R, Ahluwalia MS, Mohammadi AM, Chao ST, Barnett GH, Murphy ES, Vogelbaum MA, Angelov L, Peereboom DM and Suh J: Overall survival and the response to radiotherapy among molecular subtypes of breast cancer brain metastases treated with targeted therapies. Cancer 123: 22832293, 2017.

16 Luo J, Zhu H, Tang Y, Wang H, Zhou X, Lu X, Zhang S and Li $\mathrm{Y}$ : Analysis of prognostic factors and comparison of prognostic index scores in patients with brain metastases after whole-brain radiotherapy. Int J Clin Exp Med 7: 5217-5225, 2014.

17 Niwinska A, Murawska M and Pogoda K: Breast cancer brain metastases: differences in survival depending on biological subtype, RPA RTOG prognostic class and systemic treatment after whole-brain radiotherapy. Ann Oncol 21: 942-948, 2010.

18 Herrlinger U, Förschler H, Küker W, Meyermann R, Bamberg M, Dichgans $\mathrm{J}$ and Weller M: Leptomeningeal metastasis: survival and prognostic factors in 155 patients. J Neurol Sci 223: 167-178, 2004.

19 Bergmann M, Puskas Z and Kuchelmeister K: Subdural hematoma due to dural metastasis: case report and review of the literature. Clin Neurol Neurosurg 94: 235-240, 1992.

20 Da Silva AN and Schiff D: Dural and skull base metastases. Cancer Treat Res 136: 117-141, 2007.

21 Coleman RE: Metastatic bone disease: clinical features, pathophysiology and treatment strategies. Cancer Treat Rev 27: 165-176, 2001.

22 Monje ML, Mizumatsu S, Fike JR and Palmer TD: Irradiation induces neural precursor-cell dysfunction. Nat Med 8: 955-962, 2002.

23 Gondi V, Tolakanahalli R, Mehta MP, Tewatia D, Rowley H, Kuo JS, Khuntia D and Tomé WA: Hippocampal-sparing wholebrain radiotherapy: a "how-to" technique using helical tomotherapy and linear accelerator-based intensity-modulated radiotherapy. Int J Radiat Oncol Biol Phys 78: 1244-1252, 2010.

24 Brown PD, Pugh S, Laack NN, Wefel JS, Khuntia D, Meyers C, Choucair A, Fox S, Suh JH, Roberge D, Kavadi V, Bentzen SM, Mehta MP and Watkins-Bruner D. Radiation Therapy Oncology Group (RTOG): Memantine for the prevention of cognitive dysfunction in patients receiving whole-brain radiotherapy: a randomized, double-blind, placebo-controlled trial. Neuro Oncol 15: 1429-1437, 2013.
Received September 14, 2018

Revised September 21, 2018

Accepted September 28, 2018 